\title{
Experimental Thermal Analysis of Diesel Engine Piston and Cylinder Wall
}

\author{
Subodh Kumar Sharma, ${ }^{1}$ P. K. Saini, ${ }^{2}$ and N. K. Samria ${ }^{3}$ \\ ${ }^{1}$ Department of Mechanical Engineering, Krishna Institute of Engineering \& Technology, Ghaziabad 201206, India \\ ${ }^{2}$ Department of Mechanical Engineering, National Institute of Technology Kurukshetra, Kurukshetra 136118, India \\ ${ }^{3}$ Department of Mechanical Engineering, Banaras Hindu University, Varanasi 221002, India
}

Correspondence should be addressed to Subodh Kumar Sharma; subodhmeerut@gmail.com

Received 1 August 2014; Accepted 19 January 2015

Academic Editor: Mariatti Jaafar

Copyright (C) 2015 Subodh Kumar Sharma et al. This is an open access article distributed under the Creative Commons Attribution License, which permits unrestricted use, distribution, and reproduction in any medium, provided the original work is properly cited.

Knowledge of piston and cylinder wall temperature is necessary to estimate the thermal stresses at different points; this gives an idea to the designer to take care of weaker cross section area. Along with that, this temperature also allows the calculation of heat losses through piston and cylinder wall. The proposed methodology has been successfully applied to a water-cooled four-stroke direct-injection diesel engine and it allows the estimation of the piston and cylinder wall temperature. The methodology described here combines numerical simulations based on FEM models and experimental procedures based on the use of thermocouples. Purposes of this investigation are to measure the distortion in the piston, temperature, and radial thermal stresses after thermal loading. To check the validity of the heat transfer model, measure the temperature through direct measurement using thermocouple wire at several points on the piston and cylinder wall. In order to prevent thermocouple wire entanglement, a suitable pathway was designed. Appropriate averaged thermal boundary conditions such as heat transfer coefficients were set on different surfaces for FE model. The study includes the effects of the thermal conductivity of the material of piston, piston rings, and combustion chamber wall. Results show variation of temperature, stresses, and deformation at various points on the piston.

\section{Introduction}

For proper functioning of the internal combustion diesel engine, accurate piston temperature distribution is required because piston temperature has an important influence on ignition process of engine, ignition time delay, rate of burning, thermal efficiency, and production of pollutants. Knowledge of heat transfer in internal combustion engines is important to understand such systems $[1,2]$. It contributes to engine development and design, processes simulation, and emissions reduction. In engine piston experiences high forces due to combustion chamber pressure and thermal load, which come from combustion process and from the huge temperature gradient between intake and exhaust gas flows [3-6] so, it is important to guarantee the durability of engine components like piston, piston rings, valves, and cylinder wall, to avoid engine body distortions and to improve engine design related to weight and auxiliary energy consumption. In the case of the engine piston and cylinder, such knowledge is indispensable to have a thorough understanding of heat flux, temperature, and the distribution of these parameters. A common procedure used by some authors is to approximate the mean temperature of the distribution with one or more (very few) local measurements obtained by thermocouples $[1,7]$. These approaches implicitly assume errors that can be acceptable for heat balances but can lead to uncertainties in simulation cycles or temperature distribution analyses. Many of these models include the gas-side wall temperature as a variable to obtain the heat flux through the cylinder walls [8]. Numerous mathematical models have been proposed including correlations based on dimensional analysis, which are widely accepted. Although the models propose different 
TABLE 1: Engines and their specification.

\begin{tabular}{lccc}
\hline Specification & Type & Specification & Type \\
\hline Cooling & Water-cooled engine & Governing & Class “B1" \\
Model & AV1 & Power rating & $5 \mathrm{hp}$ \\
Number of cylinders & 1 & Fuel injection & Direct injection \\
Cubic capacity (ltr) & 0.553 & Rated speed (rpm) & 1500 \\
\hline \multicolumn{2}{c}{ Overall dimensions of the standard engine } & $617 \times 504 \times 843(L \times B \times H)$ \\
\hline
\end{tabular}

heat fluxes, their evolution over the cycle is similar. In addition, finite element method (FEM) codes used for heat transfer simulations require the estimation of temperature to provide boundary conditions where convergence is attained through an iterative process [7]. A finite element model of gasoline spark engine is successfully developed and simulated and had analyzed heat transfer during combustion process and obtains temperature distribution across the major engine component [9]. Furthermore, thermal analyses require the gas-side wall temperature to evaluate temperature distribution and the thermomechanical behaviour of components with the use of thermal barrier coating [1013]. Other researchers, having identified one correlation for one small-scale air-cooled engine [14], acknowledge that these correlation parameters are not valid for another smallscale air-cooled engine with similar characteristics [15]. In most heat transfer analyses the external surface temperatures from which heat is extracted are not measured. This is the case for water-cooled engines, where this temperature is often assumed to be equal to the coolant temperature or is calculated from hypotheses that are specific for water-cooled engines [16] and normally assume constant temperature for all operating points. This approach cannot be extrapolated to air-cooled engines because the temperature field in the inner surface changes with the operating conditions [17]. Some studies concerning heat transfer in air-cooled engines have been published and most of them consider two-stroke and/or spark-ignition engines [18-20].

In this paper a methodology is proposed for the estimation of the temperatures in piston and cylinder wall, piston body distortions, and radial stresses of a water-cooled fourstroke single cylinder direct injection diesel engine. These temperatures were obtained by simulation and experimental setup with the help of thermocouples and other sensors and other calculations that are particularized to that engine.

\section{Engine Description and Experimental Procedure}

The experimental investigation was conducted on a fourstroke single-cylinder direct-injection (DI) compression ignition engine. The main characteristics of this engine are given in Table 1 and a cutaway view of the piston and cylinder is shown in Figure 1. The experimental measurements covered four different loading conditions, namely, no load, half load, three-quarters load, and full engine load. The temperature of the piston can be estimated by direct measurement using thermocouple as well as with the help of numerical method, which consists of finite element analysis method. The purpose is to obtain a generalized method (FEM) for analyzing temperature field, piston distortion, and corresponding thermal stresses so simulated temperatures are to be verified by direct measured temperatures.

In this work, seven thermocouples were used, in which four thermocouples were mounted on the piston inner surface and three were mounted on the cylinder wall as shown Figure 2. The coordinates of these seven nodal points where thermocouples were attached are shown in Table 2. In the experimental setup engine, piston is made of aluminium alloys of MSFC-388-T5 having a thermal conductivity equal to $136 \mathrm{~W} / \mathrm{mK}$.

For direct measurement of the temperature at piston inner surface a four-bar mechanism was designed, which is shown in Figure 3. With the help of this four-bar mechanism, thermocouple wires safely come out from the engine chamber. Complete experimental setup has been shown in Figure 4. By installing thermocouple at seven points on piston and cylinder wall, variation in temperature of piston and cylinder wall at no load, half load, three-quarters load, and full load conditions was determined. For analysis of stresses and distortion of the piston, two sections 1-1 and 2-2 have been chosen as shown in Figure 1.

\section{Thermomechanical FE Analysis}

The method is based on the subdivision of the structures into elements with mathematically defined characteristics. Characters of the complex structure are then solved with the aid of computer using matrix algebra. The input data consist of loading conditions on subdivided structures or mesh constraints with physical properties of the material. Thermal loading involves the initial calculations of temperatures using boundary conditions on gas side, coolant side, and air side of piston cylinder. The analysis presented in this paper is divided into two sections, the temperature field distribution and the thermal stresses. The finite element technique with triangular element is used to reduce the variational formulation to a set of algebraic equations. The expressions to calculate nodal temperatures and the corresponding thermal stresses at every element are derived. The construction of finite element approach starts from the variational statement of the problem and then using proper shape function a number of algebraic equations are developed which are equal to the number of nodal elements in the problem domain. Then by minimizing the approximate function a set of governing 
TABLE 2: Nodal points with coordinates.

\begin{tabular}{lccccccc}
\hline Nodal point & 1 & 2 & 3 & 4 & 5 & 6 \\
\hline$r$ (radial) $(\mathrm{m})$ & 0.0360 & 0.0360 & 0.0360 & 0.0 & 0.0480 & 0.0480 \\
$z$ (axial) $(\mathrm{m})$ & 0.0075 & 0.0375 & 0.0675 & 0.075 & 0.090 & 0.0500 & 0.0050 \\
\hline
\end{tabular}
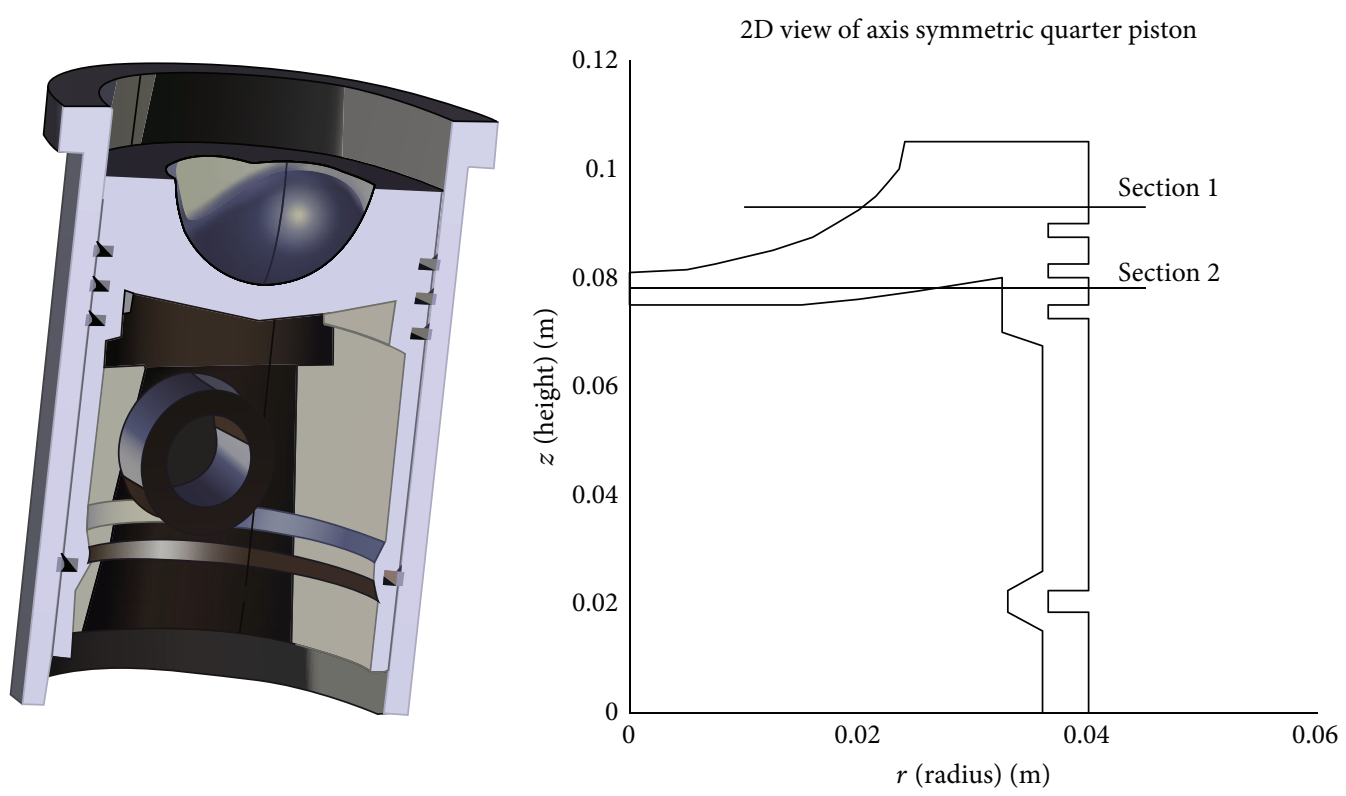

Figure 1: Cutaway view of the piston and cylinder.
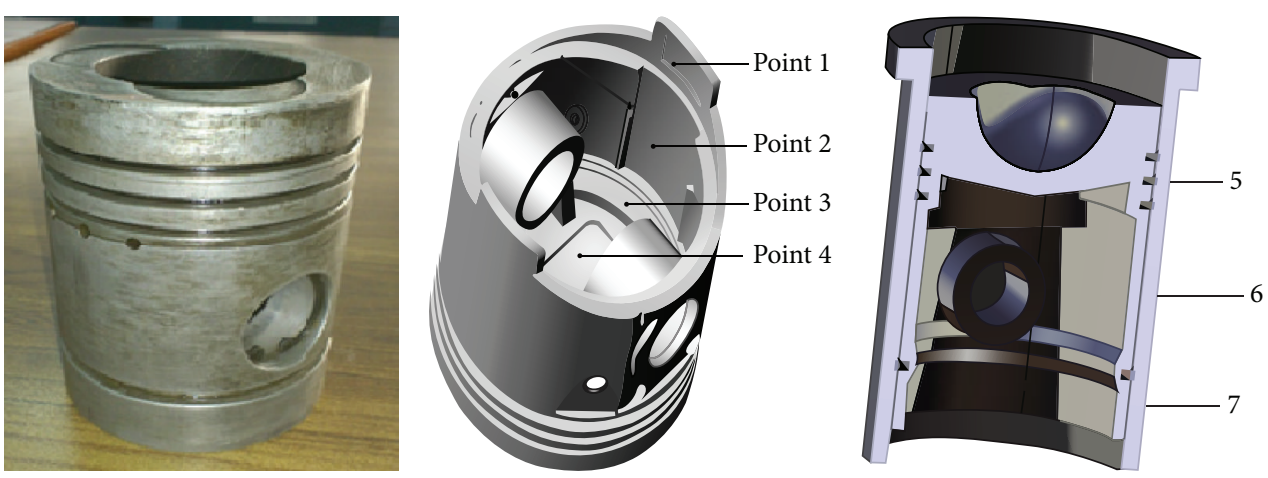

Figure 2: AV1 diesel engine piston.

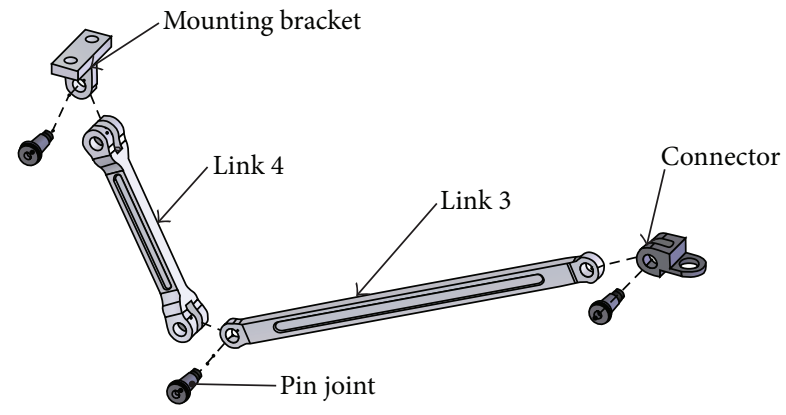

FiguRe 3: Four-bar mechanism. equation is developed for the piston and cylinder assembly. These equations are solved by using computer. Computer algorithm and a FORTRAN program code are developed to solve these equations in order to find the unknown parameters, that is, temperature at different nodal points of the piston. Computer program is based on heat transfer through conduction, convection, matrix multiplication, matrix inversion, heat flow, and stiffness. By using these subroutine and main program, temperatures and heat flow field were calculated. Mathematical modeling of conduction equation, convection equation, and contact heat transfer equation has been done which is shown below. 

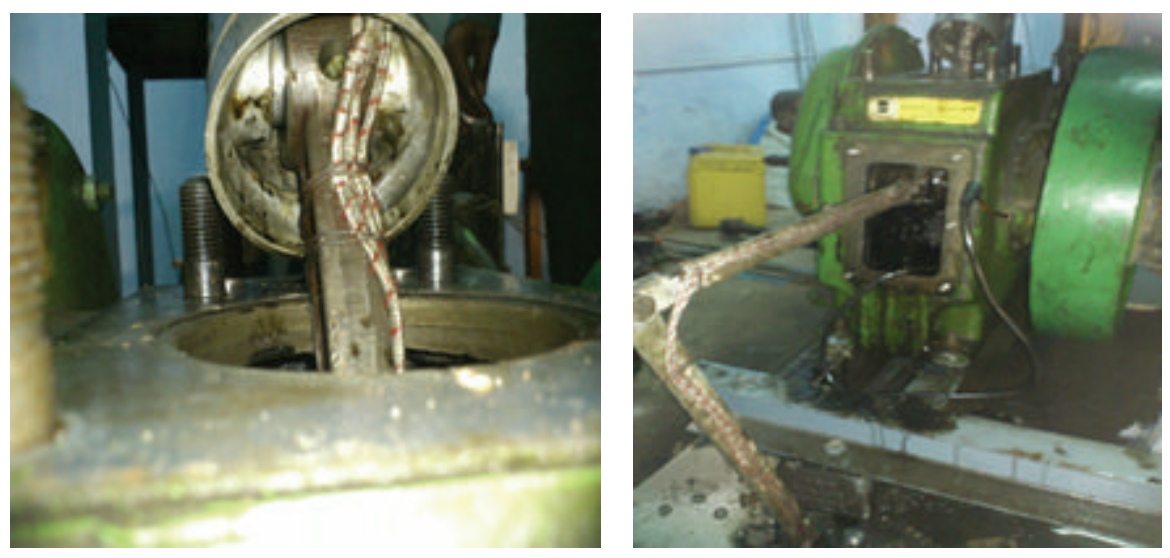

FIGURE 4: Experimental setup.

The generalized governing differential equation for heat conduction can be represented as $[7,21]$

$$
K \nabla^{2} T+q_{E}-\rho C \frac{\partial T}{\partial t}=0
$$

where $K$ is thermal conductivity in radial $(r)$ and axial $(z)$ direction, respectively. $q_{E}$ is heat conduction per unit volume. $\rho$ is density of the material. $C$ is heat capacity of the material. $T$ is temperature. $t$ is time.

The variational formulation for conductive boundary can be represented as $[7,21]$

$$
\frac{\partial \chi_{k}^{(e)}}{\partial\{t\}^{(e)}}=\left[\left[\begin{array}{lll}
k_{11} & k_{12} & k_{13} \\
k_{21} & k_{22} & k_{23} \\
k_{31} & k_{32} & k_{33}
\end{array}\right]\right]\left\{\begin{array}{l}
t_{i} \\
t_{j} \\
t_{k}
\end{array}\right\}=[k]^{(e)}\{t\}^{(e)},
$$

where $[k]^{(e)}=$ stiffness matrix.

The generalized governing differential equation for contact boundary can be represented as $[7,21]$

$$
q_{c}=h_{c}\left(T^{e}-T^{p}\right) .
$$

The variational formulation for contact boundary between 2 elements $(e)$ and $(p)$ can be written as

$$
\chi_{\text {bcont. }}=\frac{h_{c}}{2} \int_{s i}^{s j}\left[\{t\}^{e}-\{t\}^{p}\right]^{2} 2 \pi r d s .
$$

On solving it further in similar fashion as done in convective boundary, it has been found that contact boundary variational integral of heat transfer after differentiation with respect to temperature of contact surface yields a set of linear equations as a contribution to the global set of equation. Consider

$$
\begin{aligned}
\frac{\left(\partial \chi_{\text {bcont. }}\right) e}{\partial\left\{t_{s}\right\}^{e}}= & \frac{2 \pi h_{c} r_{m} r_{i j}}{6 \cos \theta}\left[\begin{array}{cc}
2-\frac{\varepsilon}{2} & 1 \\
1 & 2+\frac{\varepsilon}{2}
\end{array}\right] \\
& \cdot\left\{\begin{array}{l}
\left\{\left\{t_{s}\right\}^{e}-\left\{t_{s}\right\}^{p}\right\}_{1} \\
\left\{\left\{t_{s}\right\}^{e}-\left\{t_{s}\right\}^{p}\right\}_{2}
\end{array}\right\} .
\end{aligned}
$$

The generalized governing differential equation for heat convection can be represented as $[7,21]$

$$
-K\left(\frac{\partial T}{\partial n}\right)=h\left(T-T_{\infty}\right)
$$

The variational formulation for convective boundary can be represented as

$$
\begin{gathered}
\delta \chi_{\text {bconv. }}=\int_{A}-K\left(\frac{\partial T}{\partial n}\right) \delta T d S=\int_{A} h\left(T-T_{\infty}\right) \delta T d S, \\
\frac{\partial \chi_{\text {bconv. }}}{\partial\left\{t_{s}\right\}}=\frac{2 \pi h r_{m} r_{i j}}{6 \cos \theta}\left[\begin{array}{cc}
2-\frac{\varepsilon}{2} & 1 \\
1 & 2+\frac{\varepsilon}{2}
\end{array}\right]\left\{\begin{array}{c}
t_{s i} \\
t_{s j}
\end{array}\right\}-\left\{\begin{array}{l}
\left(h t_{\infty}\right)_{1} \\
\left(h t_{\infty}\right)_{2}
\end{array}\right\},
\end{gathered}
$$

where

$$
\begin{gathered}
r_{m}=\frac{r_{i}+r_{j}}{2}, \quad r_{i j}=r_{j}-r_{i}, \quad r_{j}=r_{m}-\frac{r_{i j}}{2}, \\
\varepsilon=\frac{r_{i j}}{r_{m}}, \\
\frac{\partial \chi_{\text {bconv. }}}{\partial\left\{t_{s}\right\}}=[H]_{s}\{t\}_{s}-\left\{h t_{\infty}\right\} .
\end{gathered}
$$

From (2), (5), and (9) variational integral of heat transfer globally is developed and represented as follows:

$$
\frac{\partial\{\chi\}^{g}}{\partial\{t\}^{g}}=\sum_{e=1}^{N}[K]^{e}\{t\}^{e}+[H]^{e}\{t\}^{e}-\left\{h t_{\infty}\right\}^{e}=0 .
$$

This equation can be written in its popular form as

$$
([K]+[H])\{T\}=\left\{h_{f}\right\} .
$$

Here $[K]$ is conduction matrix, $[H]$ is convection matrix, $\{T\}$ is unknown temperature column vector at all nodal points, and $\left\{h_{f}\right\}$ is a column vector of known quantity. All above matrixes are global matrix of size $(N \times N)$, where $N$ is the number of nodes. The column vector $\left\{h_{f}\right\}$ is of size $(N \times 1)$. 
From (11), temperatures at all the nodes of the piston are to be found out, which is to be represented in Figures 7-10.

After prediction of the temperature at all the nodes of the piston, radial thermal stress will be analyzed with the help of (12), (13), and (14) to show the radial strain, angular strain, and axial strain, respectively, as follows:

$$
\begin{gathered}
\varepsilon_{r}=\frac{\sigma_{r}}{E}-\frac{v}{E} \sigma_{\theta}-\frac{v}{E} \sigma_{z}+\alpha_{t}\left(T-T_{0}\right), \\
\varepsilon_{\theta}=-v \frac{\sigma_{r}}{E}+\frac{1}{E} \sigma_{\theta}-\frac{v}{E} \sigma_{z}+\alpha_{t}\left(T-T_{0}\right), \\
\varepsilon_{z}=-v \frac{\sigma_{r}}{E}-\frac{v}{E} \sigma_{\theta}+\frac{1}{E} \sigma_{z}+\alpha_{t}\left(T-T_{0}\right) .
\end{gathered}
$$

Thus stress strain relationship can be represented in matrix form as shown in

$$
\begin{aligned}
& {\left[\begin{array}{ccc}
1 & -v & -v \\
-v & 1 & -v \\
-v & -v & 1
\end{array}\right]\left\{\begin{array}{l}
\sigma_{r} \\
\sigma_{\theta} \\
\sigma_{z}
\end{array}\right\}=E\left[\left\{\begin{array}{c}
\varepsilon_{r} \\
\varepsilon_{\theta} \\
\varepsilon_{z}
\end{array}\right\}-\alpha_{t}\left(T-T_{0}\right)\left\{\begin{array}{l}
1 \\
1 \\
1
\end{array}\right\}\right],} \\
& {[P]\{\sigma\}=E\left[\{\varepsilon\}-\left\{\varepsilon_{0}\right\}\right],}
\end{aligned}
$$

where $[P]$ is the position matrix, $\sigma_{r}=$ radial stress, $\sigma_{\theta}=$ angular stress, and $\sigma_{z}=$ axial stress. After inversion of position matrix, put the value of this in the above equation and find the stresses at all the nodes of the piston. Consider

$$
\begin{gathered}
\{\sigma\}=[P]^{-1} E\left[\{\varepsilon\}-\left\{\varepsilon_{0}\right\}\right], \\
{[P]^{-1}=\frac{(1+v)(1-v)}{(1+v)^{2}(1-2 v)}\left[\begin{array}{ccc}
1 & v_{1} & v_{1} \\
v_{1} & 1 & v_{1} \\
v_{1} & v_{1} & 1
\end{array}\right],} \\
\sigma=\frac{E(1-v)}{(1-2 v)(1+v)}\left[\begin{array}{ccc}
1 & v_{1} & v_{1} \\
v_{1} & 1 & v_{1} \\
v_{1} & v_{1} & 1
\end{array}\right]\left[\{\varepsilon\}-\left\{\varepsilon_{0}\right\}\right],
\end{gathered}
$$

where $\sigma=$ thermal stress, thermal strain $\left\{\varepsilon_{0}\right\}=\alpha_{t}\left(T-T_{0}\right)$, and simple strain $\{\varepsilon\}=\left\{\begin{array}{c}\varepsilon_{r} \\ \varepsilon_{\theta} \\ \varepsilon_{z}\end{array}\right\} ; v$ is the Poisson ratio and it is 0.33 and $v_{1}=v /(1-v)$.

From (12), (14), and (19), radial displacement, axial displacement, and radial thermal stresses at all the nodes of the piston have been calculated and are represented in Figures $11-16$.

3.1. Finite Element Formulation for Checking Heat Balance. This formulation can be used to check the heat balance of the problem. The amount of heat balanced is checked for accuracy and satisfied with result by observing that the amount of heat supplied at gas side of the piston is equal to the amount of heat loss to both water and air side of the piston.

Consider one side of element having two nodal points $i$, $j$, which faced the boundary where heat is either supplied or rejected. The formulation of the equation is as follows.

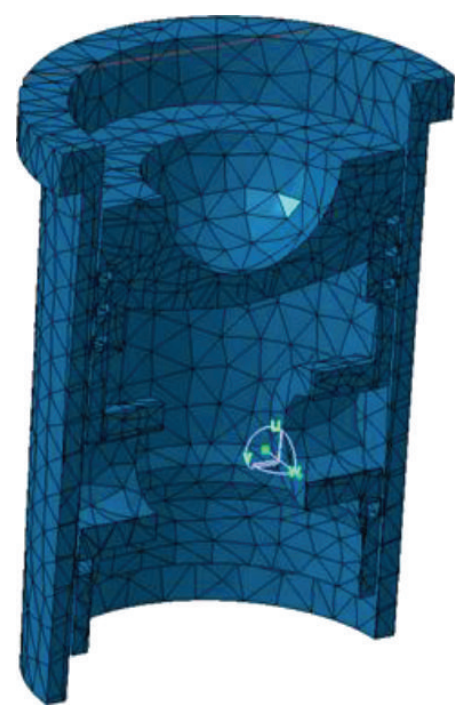

Figure 5: Meshed piston cylinder model.

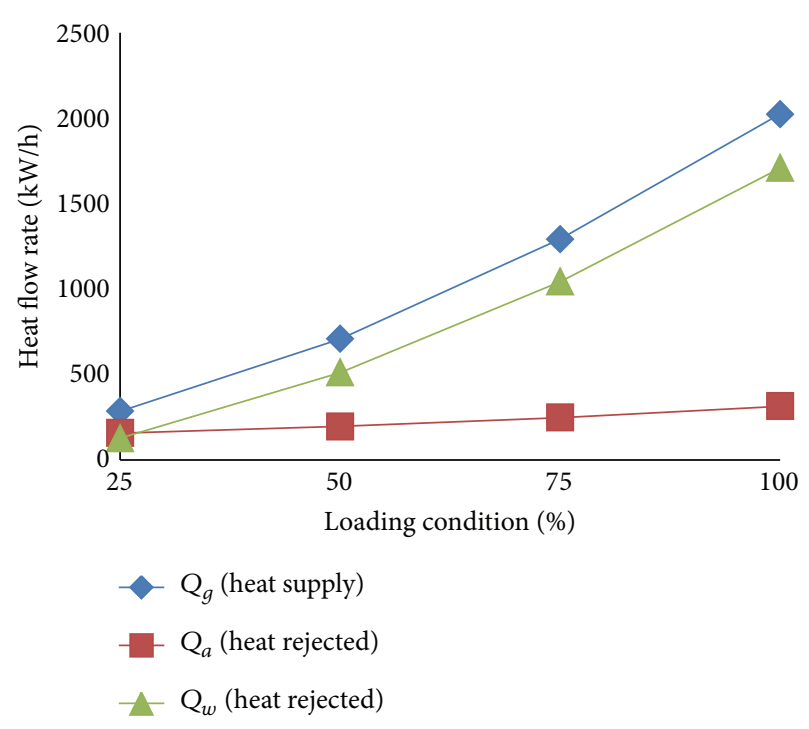

FIgURE 6: Heat flow pattern for four different load cases.

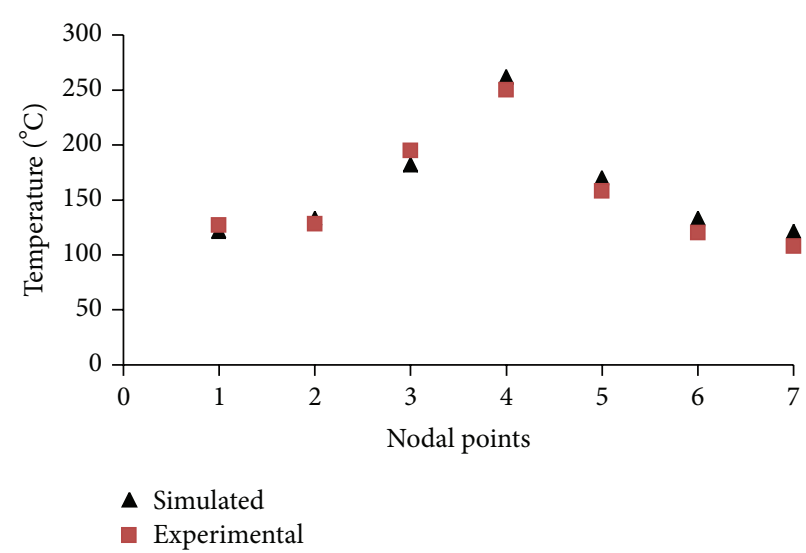

Figure 7: Temperature distribution at full load. 


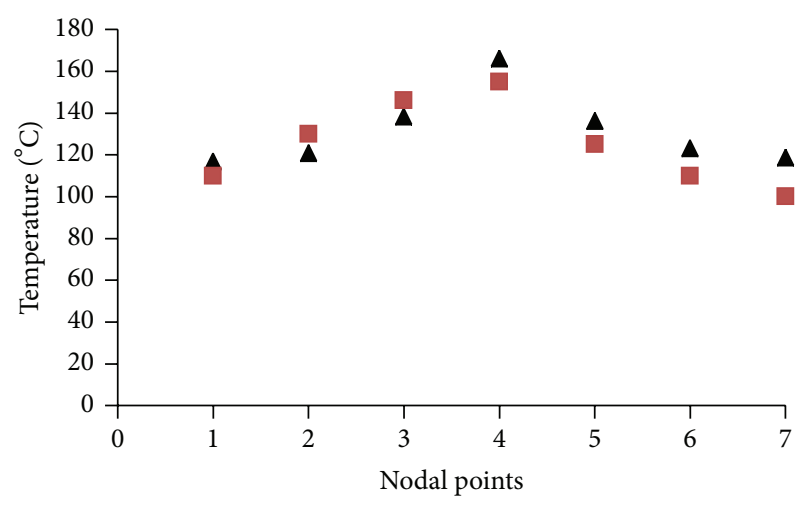

\ Simulated

- Experimental

Figure 8: Temperature distribution at three-quarters load.

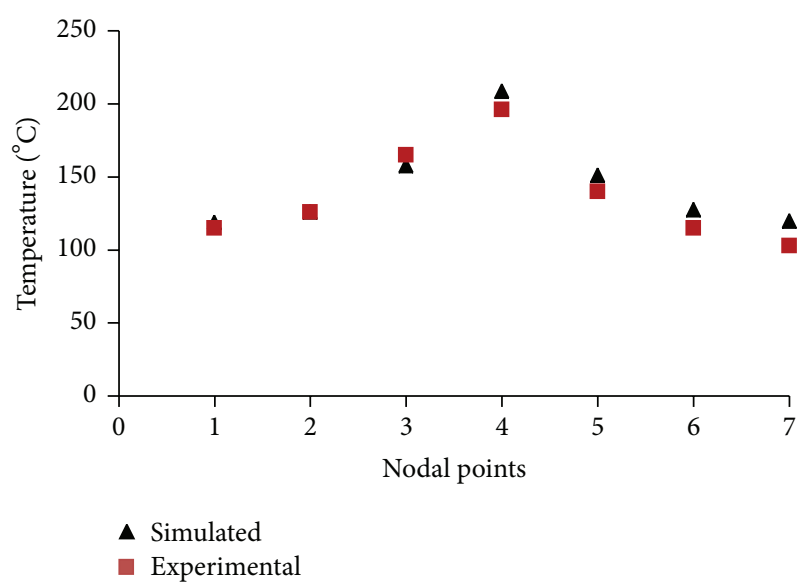

FIgure 9: Temperature distribution at half load.

The generalized heat transfer equation from connective surfaces is represented as follows:

$$
\int_{s i}^{s j} d Q=\int_{s i}^{s j} 2 \pi r h\left(t_{s}-t_{\infty}\right) d S,
$$

where

$$
\begin{gathered}
t_{s}=c_{1}+c_{2} s=\left[N_{s}\right]^{(e)}\left\{t_{s}\right\}^{(e)} \\
\int_{r_{i}}^{r_{j}} d Q=\frac{2 \pi h}{\cos \theta} \int_{r_{i}}^{r_{j}}\left(r N_{s i} t_{s i}+N_{s j} t_{s j}-t_{\infty}\right) d r
\end{gathered}
$$

where

$$
\begin{gathered}
\int_{r_{i}}^{r_{j}} r N_{s i} d r=\frac{r_{i j} r_{m}}{2}\left[1-\frac{\varepsilon}{6}\right], \\
\int_{r_{i}}^{r_{j}} r N_{s j} d r=\frac{r_{i j} r_{m}}{2}\left[1+\frac{\varepsilon}{6}\right], \\
\int_{r_{i}}^{r_{j}} r N_{\infty} d r=r_{i j} r_{m} t_{\infty} .
\end{gathered}
$$

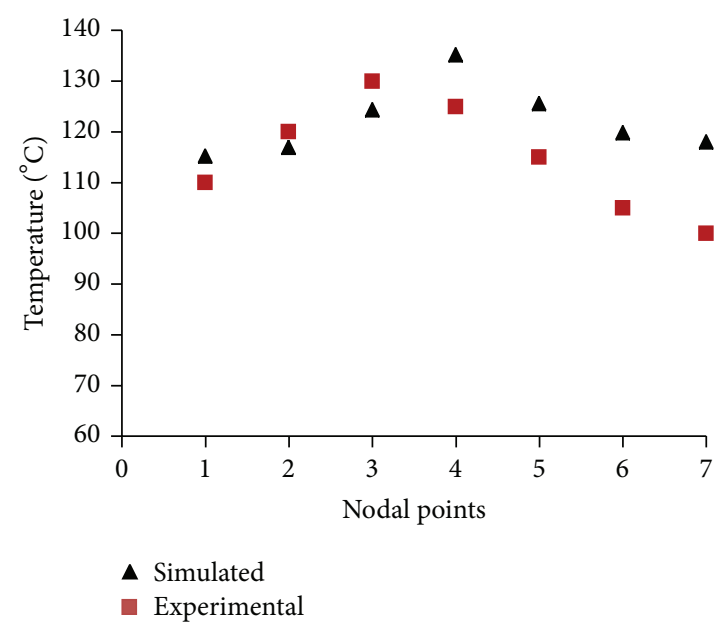

FIGURE 10: Temperature distribution at no load.

From (22), heat transfer equation is developed and represented as follows:

$$
\begin{aligned}
& Q_{s i j}= \frac{2 \pi h}{\cos \theta} \\
& \cdot\left[t_{s i}\left(1-\frac{\varepsilon}{6}\right) \frac{r_{m} r_{i j}}{2}+t_{s j}\left(1+\frac{\varepsilon}{6}\right) \frac{r_{m} r_{i j}}{2}-r_{m} r_{i j} t_{\infty}\right], \\
& Q_{s i j}=\frac{2 \pi h r_{m} r_{i j}}{\cos \theta}\left[\left(1-\frac{\varepsilon}{6}\right) \frac{t_{s i}}{2}+\left(1+\frac{\varepsilon}{6}\right) \frac{t_{s j}}{2}-t_{\infty}\right], \\
& r_{m}=\frac{r_{i}+r_{j}}{2}, \quad r_{i j}=r_{j}-r_{i}, \quad r_{j}=r_{m}-\frac{r_{i j}}{2}, \quad \varepsilon=\frac{r_{i j}}{r_{m}} .
\end{aligned}
$$

By using (24), heat transfer through the different surfaces can be determined easily. Heat transfer from piston through combustion chamber side, air side, and water side is represented by $Q_{g}, Q_{a}$, and $Q_{w}$, respectively.

\section{Development of a Geometrical and a FE Model}

A geometrical model of the piston was developed based on geometry of the actual object. Properties of the geometrical objects allowed determining such parameters as the piston diameter, the diameter of the piston pin hole, and dimensions of the piston ring grooves.

A final CAD model is presented in Figure 1. In this model, a certain geometric simplification was assumed, including missed bends with a small radius on the edge of crown and lateral surface of the head of the piston. Finally, the geometrical model was discretized into tetrahedron finite elements. Such elements had to be applied due to a complex shape of the piston. The size of finite elements was different in respective sections of the piston; larger elements were used for the piston crown and skirt, whereas the smaller ones were employed close to the oil channels. The total number of nodes and elements in the quarter portion of piston FE model was 
TABLE 3: Heat transfer parameter for four different cases of engine loading.

\begin{tabular}{lcccc}
\hline Parameter & $\begin{array}{c}\text { Case } 4 \\
\text { (full load) }\end{array}$ & $\begin{array}{c}\text { Case 3 } \\
(3 / 4 \text { load })\end{array}$ & $\begin{array}{c}\text { Case 2 } \\
\text { (half load) }\end{array}$ & $\begin{array}{c}\text { Case 1 } \\
\text { (no load) }\end{array}$ \\
\hline$T_{g}$ (combustion side) ${ }^{\circ} \mathrm{C}$ & 1000 & 800 & 600 & 400 \\
$H_{g}$ (combustion side) $\mathrm{w} / \mathrm{m}^{2} \mathrm{k}$ & 290.5 & 232.4 & 174.3 & 116.2 \\
\hline
\end{tabular}

TABLE 4: Simulated and experimental temperature.

\begin{tabular}{|c|c|c|c|c|}
\hline Loading conditions & Full load & Three-quarters load & Half load & No load \\
\hline Heat supplied from combustion gases $\left(Q_{g}\right) \mathrm{kw} / \mathrm{hr}$ & 2023.937 & 1292.542 & 708.397 & 286.428 \\
\hline Heat rejected to water $\left(Q_{w}\right) \mathrm{kw} / \mathrm{hr}$ & 1708.947 & 1043.344 & 511.921 & 128.177 \\
\hline Heat rejected to air $\left(Q_{a}\right) \mathrm{kw} / \mathrm{hr}$ & 314.883 & 249.107 & 196.388 & 158.163 \\
\hline
\end{tabular}

equal to 311 and 272, respectively. Figure 5 shows the FE discrete model of the piston.

\section{Thermal Boundary Conditions}

The thermal boundary conditions consist of applying a convection heat transfer coefficient and the bulk temperature, and they are applied to the piston crown, piston ring land sides, piston ring groove lands, and piston under crown surfaces. The temperature and heat transfer coefficients in the combustion chamber in all the loading condition were identified based on data provided in previous research paper $[7,13]$ which are presented in Table 3 . The adopted heat transfer coefficient on the contact surfaces are $H_{a}$ (heat transfer coefficient at piston under crown surface) $=174.3 \mathrm{w} / \mathrm{m}^{2} \mathrm{k}, H_{1}$ (heat transfer coefficient at ring lands and piston skirt upper and lower side) $=2905.4 \mathrm{w} / \mathrm{m}^{2} \mathrm{k}, H_{2}$ (heat transfer coefficient at ring lands and piston skirt contact surfaces) $=20 \mathrm{w} / \mathrm{m}^{2} \mathrm{k}$, $\mathrm{H}_{3}$ (heat transfer coefficient between piston rings and cylinder wall contact surfaces) $=38346 \mathrm{w} / \mathrm{m}^{2} \mathrm{k}, H_{4}$ (heat transfer coefficient between piston and cylinder wall contact surfaces) $=2324 \mathrm{w} / \mathrm{m}^{2} \mathrm{k}, H_{w}$ (heat transfer coefficient through cylinder wall to water $)=1859.2 \mathrm{w} / \mathrm{m}^{2} \mathrm{k}$, and temperature on water side $\left(T_{w}\right)$ was $120^{\circ} \mathrm{C}$ and on crank case side $\left(T_{a}\right)$ was $80^{\circ} \mathrm{C}$.

\section{Results}

The temperature distribution and heat flow field were studied with the help of finite element analysis using thermal boundary conditions. To check the validity of the heat transfer model, the heat balance approached was adopted. According to the principle of conversion of energy, at steady state condition the heat entering into the piston from gas side is equal to the heat rejected to water and heat rejected to air. Figure 6 shows the variation of heat received $\left(Q_{g}\right)$ by the piston from the hot gases, heat rejected to water $\left(Q_{w}\right)$, and heat lost to air $\left(Q_{a}\right)$ at the four different thermal loading conditions. It seems that heat received from the hot gas is increased with increase in the engine combustion temperature $\left(T_{g}\right)$. Similarly heat rejected to water and heat rejected to air increase with engine combustion temperature. Here in the present analysis the heat balance equation is satisfied for all the different loading conditions which were shown in Figure 6. In Figure 6, it

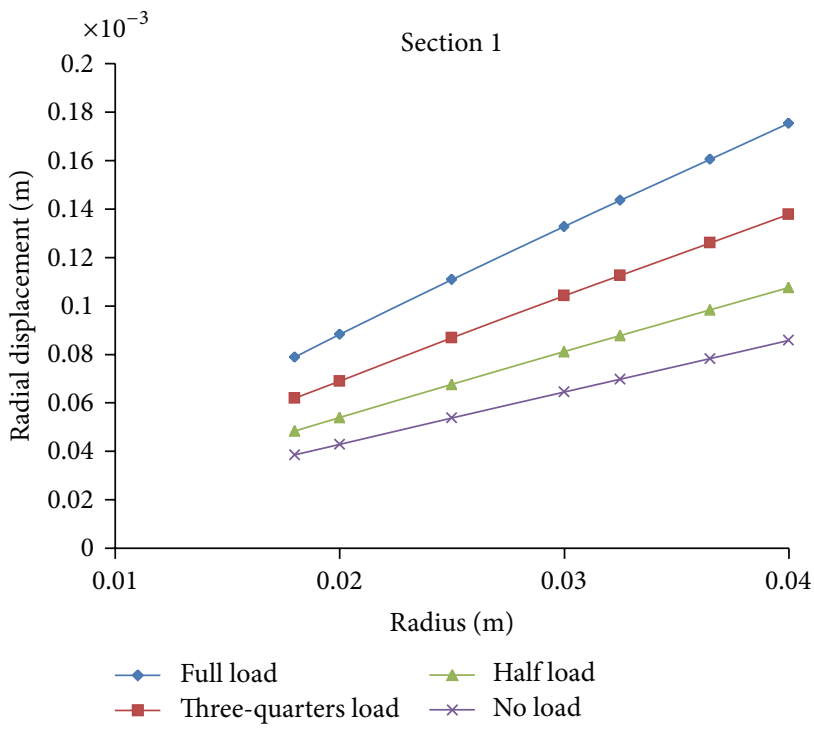

FIGURE 11: Radial displacement at section 1.

can be observed that the error is very small between heat supplied $\left(Q_{g}\right)$ by the combustion gasses and heat rejected to water $\left(Q_{w}\right)$ and air sides $\left(Q_{a}\right)$. It represents a uniform percentage throughout all the tests, shown in Table 4. As expected, for steady state conditions the heat transfer rate increases with engine loading condition, with a maximum observed at full load. Figures 7-10 show the temperature distribution. Through the analysis authors found that the maximum temperature occurs at crown of the piston, because it is exposed to the hot gases in the combustion chamber, while the minimum temperature occurs at the carter end of the piston, which is exposed to the air. These variations in temperature are mainly responsible for the development of temperature stress, causing appearance of crack in the body of the piston. Experimental setup established and measured the temperatures through temperature sensors at seven testing points (nodal points) where temperature sensors were mounted, shown in Table 5. As expected, for all load conditions the simulated and experimental measured temperature increased with engine loading condition, with a maximum observed at full load. 
TABLE 5: Simulated and experimental temperature.

\begin{tabular}{|c|c|c|c|c|c|c|c|c|}
\hline \multirow{2}{*}{ Nodal pt. } & \multicolumn{4}{|c|}{ Simulated temperature $\left({ }^{\circ} \mathrm{C}\right)$} & \multicolumn{4}{|c|}{ Experimental temperature $\left({ }^{\circ} \mathrm{C}\right)$} \\
\hline & Full load & Third-forth load & Half load & No load & Full load & Three-quarters load & Half load & No load \\
\hline 1 & 121.684 & 118.974 & 116.803 & 115.229 & 122 & 115 & 110 & 109 \\
\hline 2 & 132.963 & 126.262 & 120.892 & 117 & 130 & 126 & 124 & 120 \\
\hline 3 & 182.095 & 157.871 & 138.458 & 124.383 & 195 & 165 & 146 & 130 \\
\hline 4 & 261.799 & 208.686 & 166.104 & 135.219 & 250 & 196 & 155 & 125 \\
\hline 5 & 169.761 & 151.186 & 136.335 & 125.595 & 158 & 140 & 125 & 115 \\
\hline 6 & 133.163 & 127.587 & 123.119 & 119.88 & 120 & 115 & 110 & 105 \\
\hline 7 & 121.25 & 119.911 & 118.838 & 118.06 & 108 & 103 & 100 & 100 \\
\hline
\end{tabular}

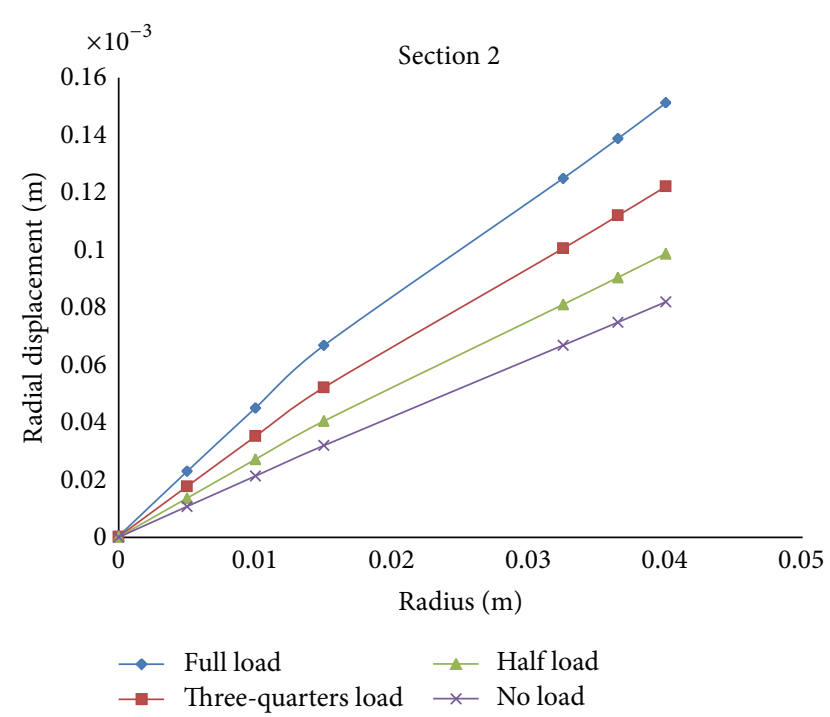

Figure 12: Radial displacement at section 2.

The nonuniform variation in temperature is solely responsible for the development of thermal strain on piston body. Initially the piston is at $25^{\circ} \mathrm{C}$ and it is assumed that initially there is no thermal strain and stresses are present. Here in the analysis first the displacement for each element is obtained and the compatibility equation is found to be satisfied. Being CST the strain in the whole element is constant and assumed to be located at the center gravity of the element. Thus an element either expands or contracts owing to its temperature variation to maintain the constant strain in whole element. The thermal strains are related to stresses by means of Hook's law of linear isothermal elastically. Thus the thermal stress developed depends directly on the mean temperature. The present analyses on two different sections on piston body are chosen to study the behavior of the stress. One section on the piston body is chosen near the piston crown (section 1) having 7 nodes and the other at bottom of the body (section 2) having 7 nodes. Figures 11 and 12 show the radial displacements of the nodal points with respect to the piston radius under four thermal loadings at section 1 and section 2, respectively. It was found that the radial displacements of the nodes of these sections are varied in increasing order from centre to the circumference of the piston in all four loading conditions. And it is observed

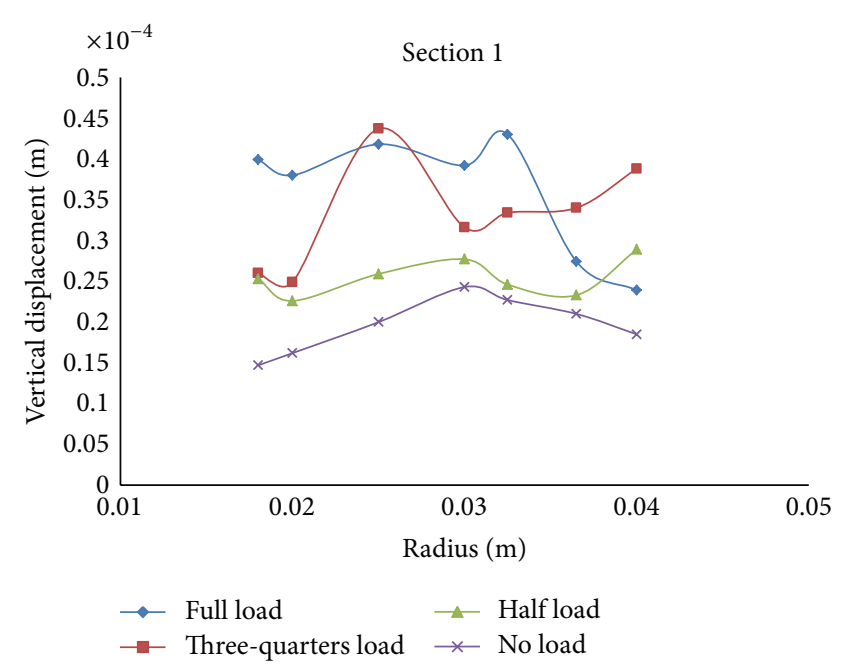

Figure 13: Vertical displacement at section 1.

that the displacement of section 1 is more than that of the section 2 due to high temperature. Figures 13 and 14 show the vertical displacement of the nodal points with respect to the piston radius under four thermal loadings at sections 1 and 2, respectively. Figures 13 and 14 indicate a sharp variation in magnitude and direction of vertical displacement of nodal elements. This is because every element tends to maintain the constant strain property. If a node expands for a certain element then it must compress for another element. Figures 15 and 16 show the variation of radial stresses with respect to the piston radius under four thermal loadings at sections 1 and 2, respectively. These stresses are introduced in the body due to high temperature. Figures 15 and 16 show a sharp variation in magnitude and direction of a radial stress. As discussed it is because every element tends to maintain the constant strain property. Thus it undergoes a simultaneous expansion or compression between two adjacent elements. However by considering a very large number of elements these sharp variations in stress can be eliminated and a more continuous curve can be obtained. Generally at high temperature piston is distorted slightly in outward direction, and this was shown in Figure 17. In this analysis, distortion in the piston body was observed at full loading condition. The maximum value of the dislocation is approximately $8 \times 10^{-5}$ 


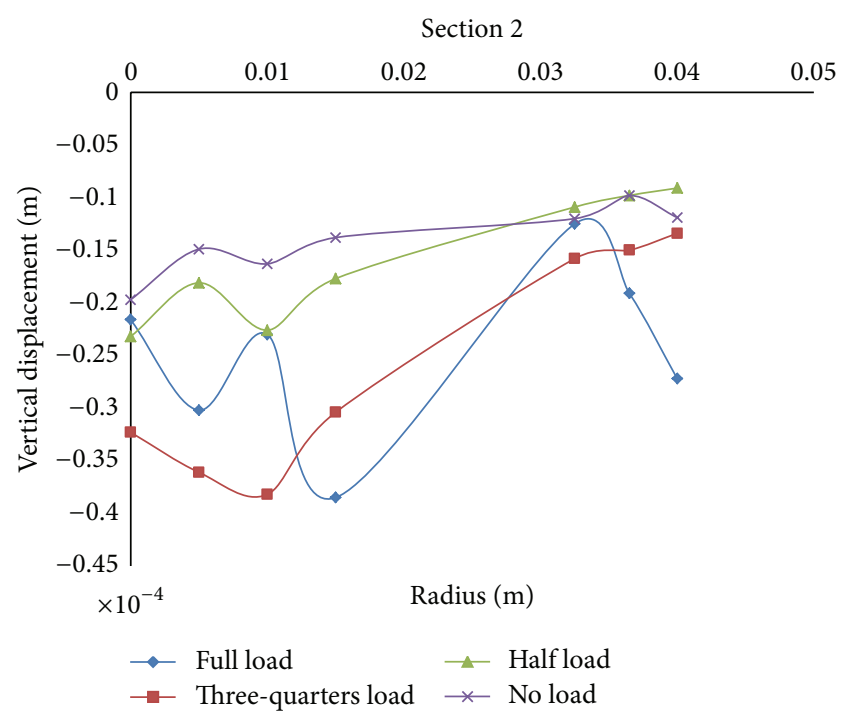

FIGURE 14: Vertical displacement at section 2.

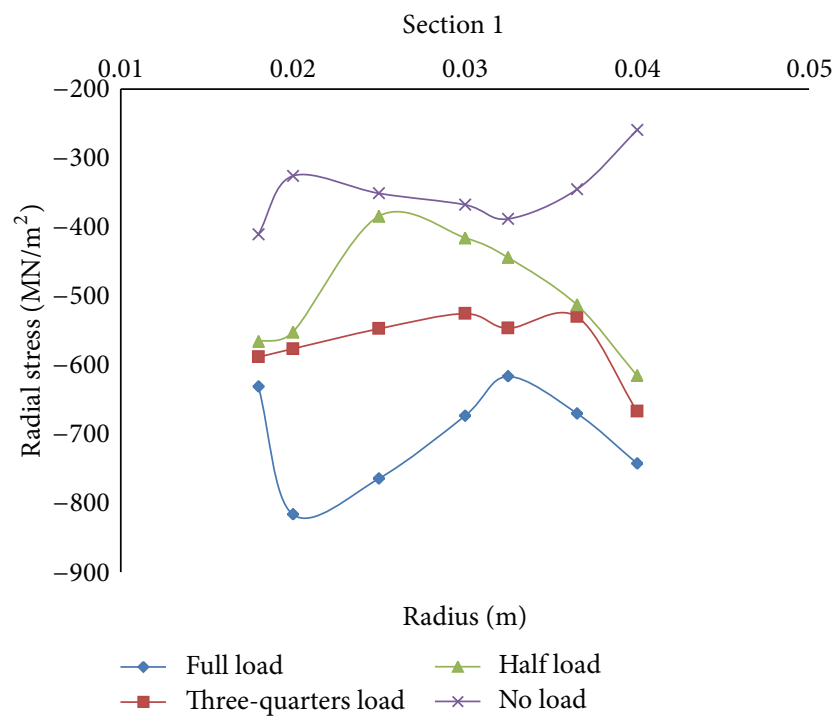

FIgURE 15: Variation in radial stresses at section 1.

meter and it was found nearer to the piston ring land sides, due to low strength at this part of the piston.

\section{Conclusions}

As engine load increases, temperature of the piston and cylinder wall increases exponentially and has a positive relationship. The piston temperature for every engine load condition tested was estimated and good agreement was obtained with the expected results. These results are also consistent with those described in the technical literature.

The proposed methodology can also be extended to determine temperatures of other components of the combustion chamber, of course taking into account its particularities. These temperatures, together with experimental measurements and the estimations calculated, can be used to obtain

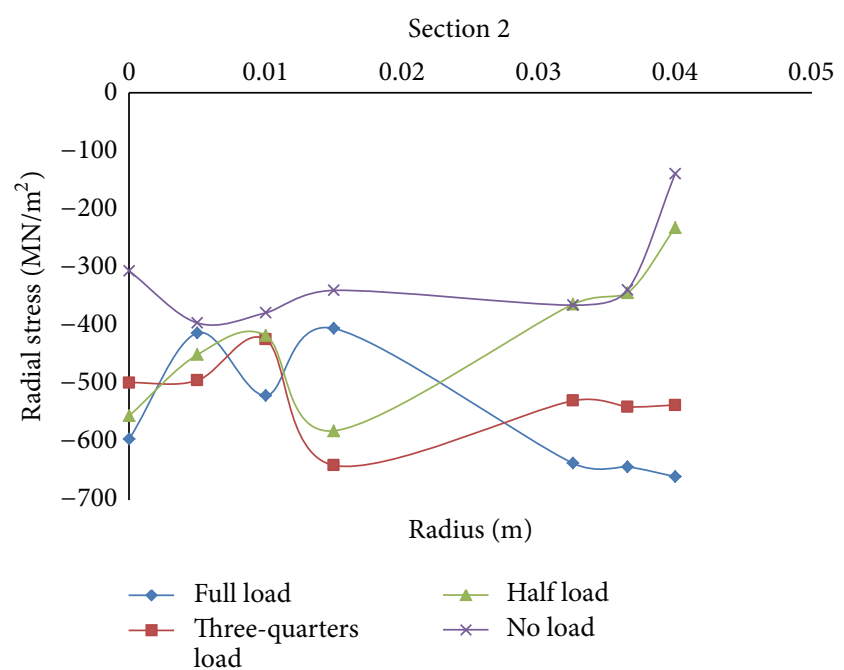

FIgURE 16: Variation in radial stresses at section 2.

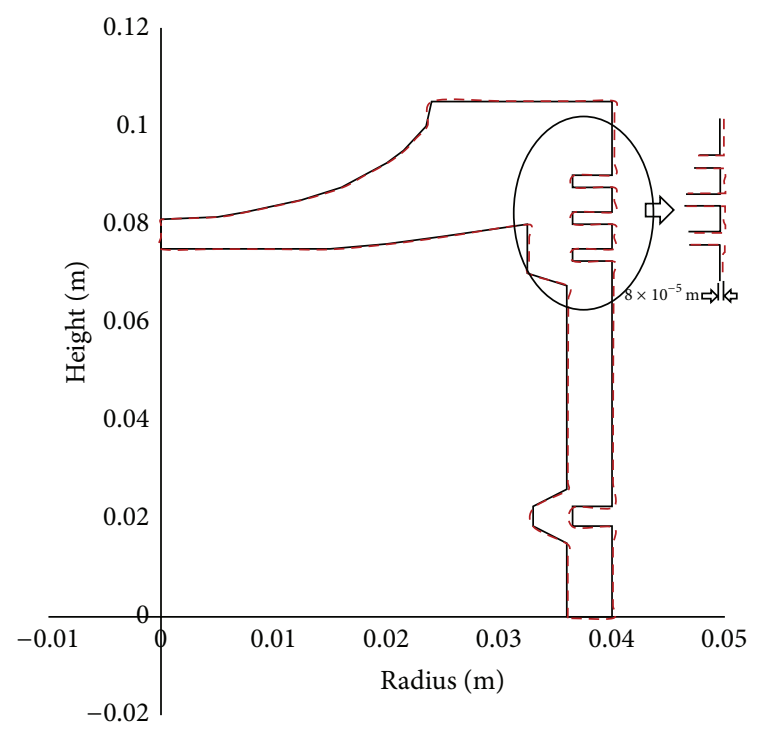

FIGURE 17: Piston distortion at full loading.

an integral heat engine losses model for the engine under analysis. The development of this integral heat transfer model is object of current research.

\section{Conflict of Interests}

The authors declare that there is no conflict of interests regarding the publication of this paper.

\section{References}

[1] J. B. Heywood, Internal Combustion Engines Fundamentals, McGraw-Hill, New York, NY, USA, 1989.

[2] R. Stone, Introduction to Internal Combustion Engines, Macmillan Press, 1999.

[3] C. F. Taylor and T. Y. Toong, "Heat transfer in internalcombustion engines," ASME Paper 57-HT-17, 1957. 
[4] G. A. Woschni, "Universally applicable equation for the instantaneous heat transfer coefficient in the internal combustion engine," SAE 670931, 1967.

[5] G. F. Hohenberg, "Advanced approaches for heat transfer calculation," SAE 790825, SAE International, 1979.

[6] J. Chang, O. Guralp, Z. Filipi et al., "New heat transfer correlation for an HCCI engine derived from measurements of instantaneous surface heat flux," SAE 2004-01-2996, 2004.

[7] S. K. Sharma, P. K. Saini, and N. K. Samria, "Modelling and analysis of radial thermal stresses and temperature field in diesel engine valves with and without air cavity," International Journal of Engineering, Science and Technology, vol. 5, no. 3, pp. 111-123, 2013.

[8] G. Borman and K. Nishiwaki, "Internal-combustion engine heat transfer," Progress in Energy and Combustion Science, vol. 13, no. 1, pp. 1-46, 1987.

[9] A. Kandil, A. A. El-Kady, and A. El-Kafrawy, “Transient thermal stress analysis of thick-walled cylinders," International Journal of Mechanical Sciences, vol. 37, no. 7, pp. 721-732, 1995.

[10] I. Taymaz, "An analysis of residual stresses in thermal barrier coatings: a FE performance assessment," Plasma Processes and Polymers, vol. 6, no. 1, pp. S599-S604, 2009.

[11] E. Buyukkaya and M. Cerit, "Thermal analysis of a ceramic coating diesel engine piston using 3-D finite element method," Surface and Coatings Technology, vol. 202, no. 2, pp. 398-402, 2007.

[12] B. Zhao, "Thermal stress analysis of ceramic-coated diesel engine pistons based on the wavelet finite-element method," Journal of Engineering Mechanics, vol. 138, no. 1, pp. 143-149, 2012.

[13] M. Cerit, "Thermo mechanical analysis of a partially ceramic coated piston used in an SI engine," Surface \& Coatings Technology, vol. 205, no. 11, pp. 3499-3505, 2011.

[14] Y. Y. Wu, B.-C. Chen, and F.-C. Hsieh, "Heat transfer model for small-scale air-cooled spark-ignition four-stroke engines," International Journal of Heat and Mass Transfer, vol. 49, no. 2122, pp. 3895-3905, 2006.

[15] Y.-Y. Wu, B.-C. Chen, F.-C. Hsieh, and C.-T. Ke, "Heat transfer model for small-scale spark-ignition engines," International Journal of Heat and Mass Transfer, vol. 52, no. 7-8, pp. 1875-1886, 2009.

[16] C. D. Rakopoulos and G. C. Mavropoulos, "Study of the steady and transient temperature field and heat flow in the combustion chamber components of a medium speed diesel engine using finite element analyses," International Journal of Energy Research, vol. 20, no. 5, pp. 437-464, 1996.

[17] D. J. Thornhill, "Experimental investigation into the temperature and heat transfer distribution around air-cooled cylinders," Tech. Rep. 2006-32-0039, SAE, 2006.

[18] C. D. Rakopoulos, K. A. Antonopoulos, D. C. Rakapoulos, and E. G. Giakoumis, "Investigation of the temperature oscillations in the cylinder walls of a diesel engine with special reference to the limited cooled case," International Journal of Energy Research, vol. 28, no. 11, pp. 977-1002, 2004.

[19] D. Descieux and M. Feidt, "One zone thermodynamic model simulation of an ignition compression engine," Applied Thermal Engineering, vol. 27, no. 8-9, pp. 1457-1466, 2007.

[20] Y. Zhaoda, F. Zheng, Y. Siaoli, Y. Zhixing, and S. Hongouan, "Calculation and prediction of thermal loading of the air cooled diesel engine," SAE 881254, SAE International, 1988.
[21] R. Prasad and N. K. Samria, "Transient heat transfer analysis in an internal combustion engine piston," Computers \& Structures, vol. 34, no. 5, pp. 787-793, 1990. 

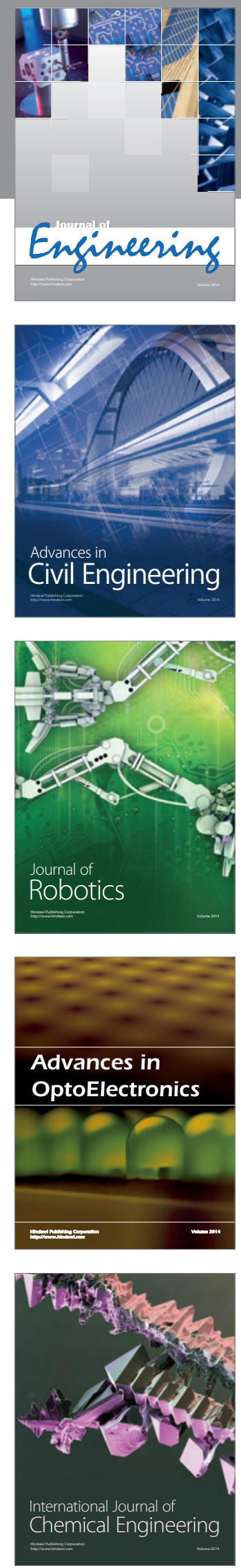

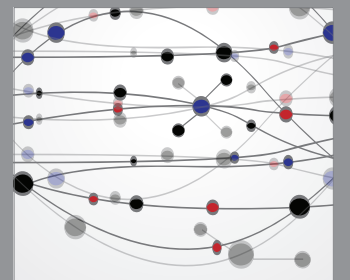

The Scientific World Journal
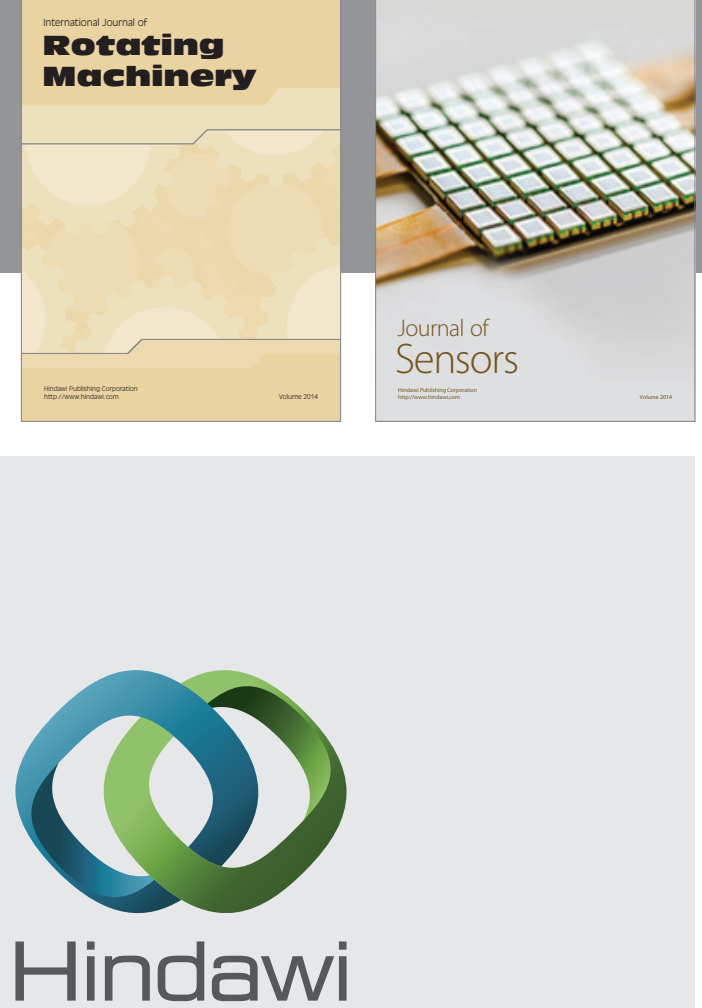

Submit your manuscripts at http://www.hindawi.com
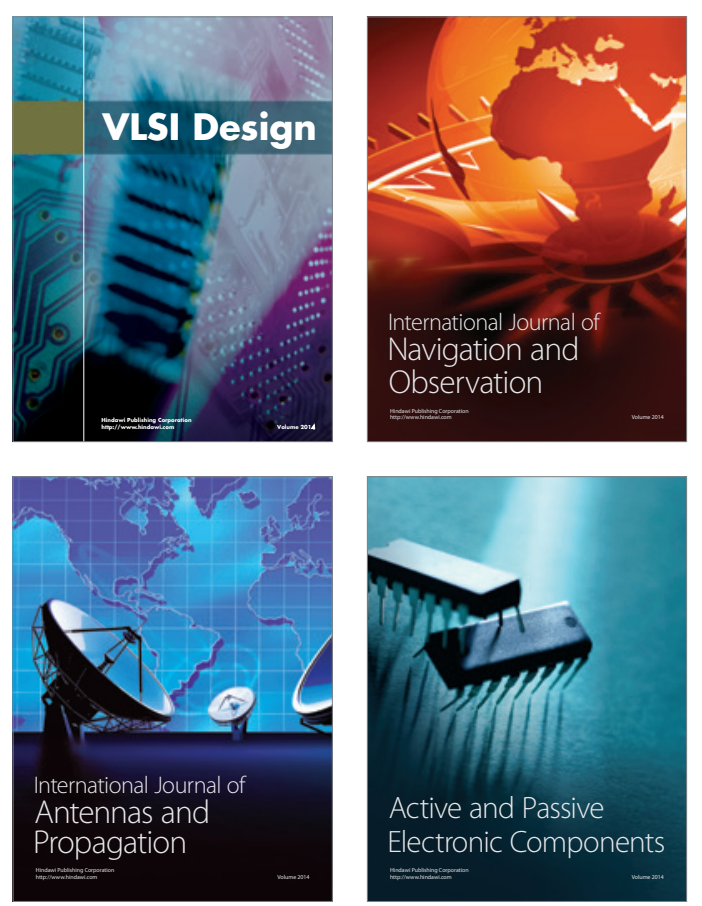
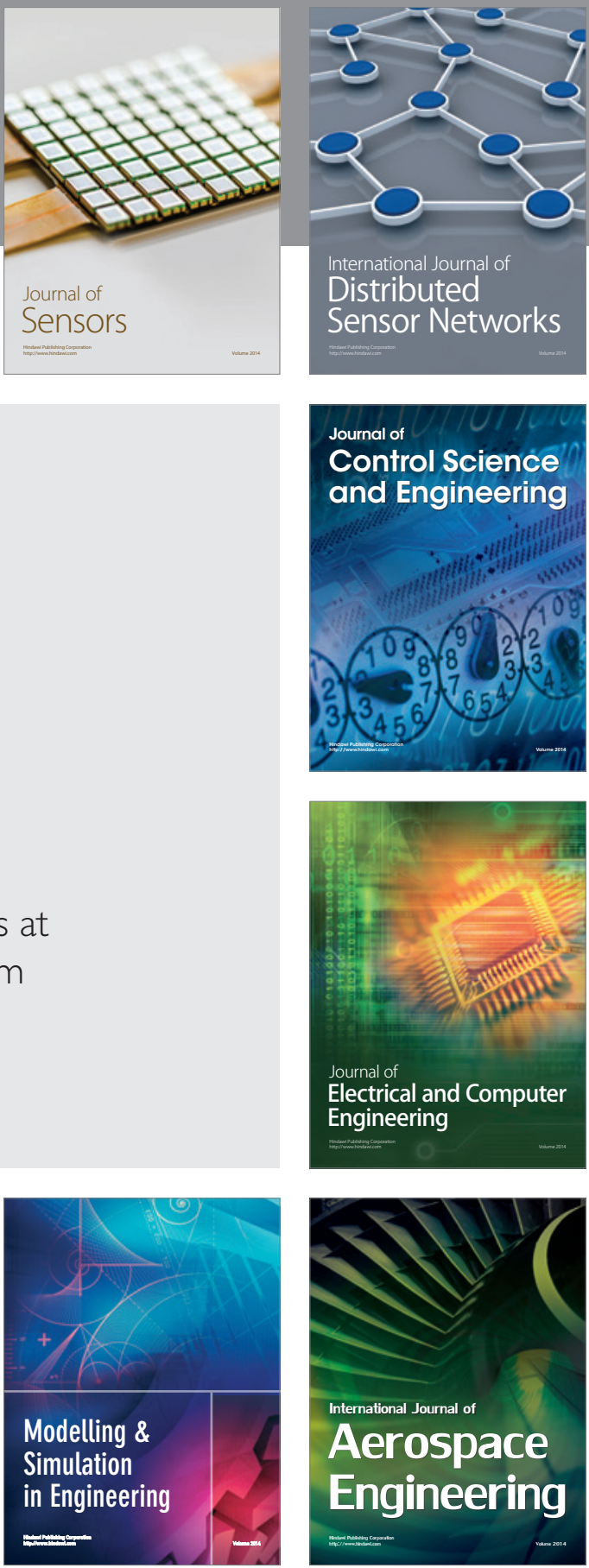

Journal of

Control Science

and Engineering
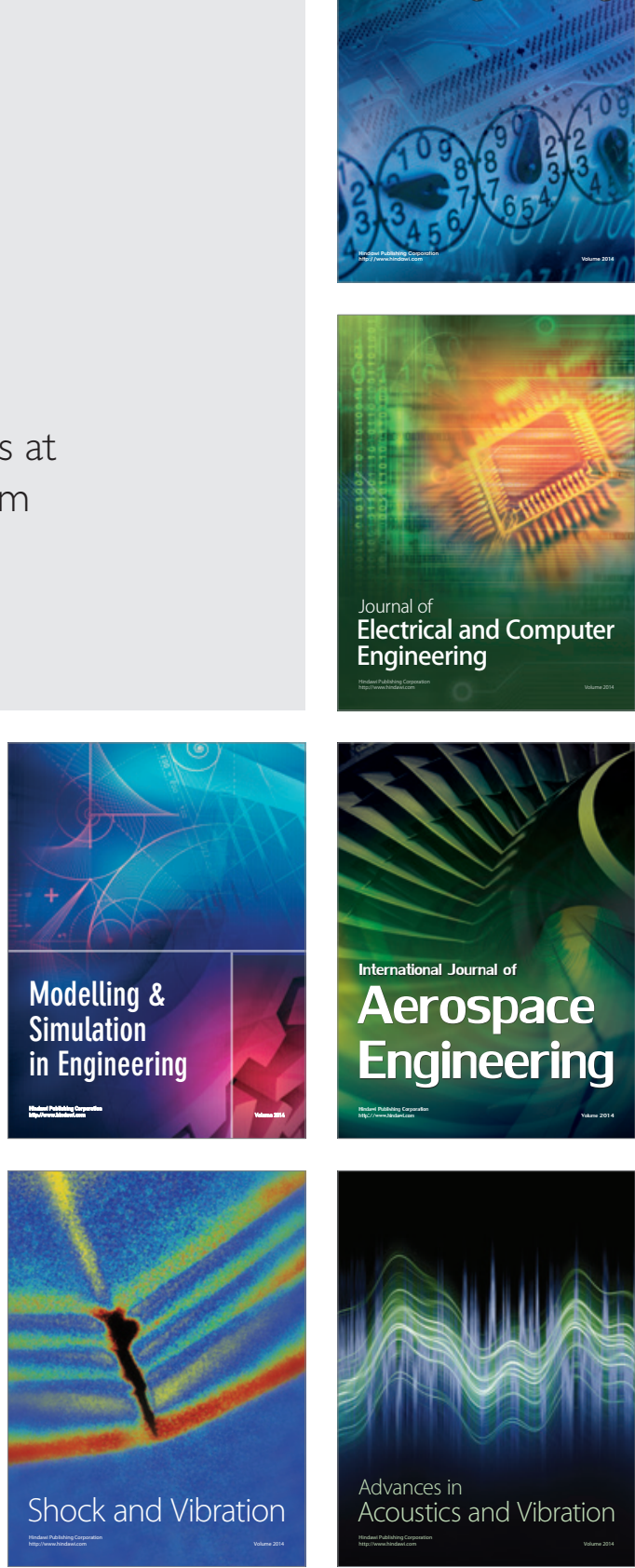